\title{
Foraging behavior and prey selection of the leather seastar Dermasterias imbricata
}

\author{
Cynthia Annett* and Raymond Pierotti*
}

Moss Landing Marine Laboratory, Moss Landing, California 95039, USA

\begin{abstract}
Stomach contents of 243 Dermasterias imbricata (Grube) from 2 field sites in Monterey Bay, central California (USA), revealed a diet consisting primarily of the corallimorphian anemone Corynactis californica. A survey of potential prey species demonstrated that $C$. californica were found in $85 \%$ of 52 randomly placed $1 / 4 \mathrm{~m}^{2}$ quadrats and $96 \%$ of $451 / 4 \mathrm{~m}^{2}$ quadrats placed around $D$. imbricata within our study area. All other species of anemones were either rare or absent from the study area, with the exception of a few large individuals. When presented with a choice between $C$. californica and Anthopleura elegantissima or A xanthogrammica in the laboratory, $D$. imbricata consistently ate the Anthopleura spp. and avoided $C$. californica. In single prey presentations, $A$. elegantissima, A. xanthogrammica, and Metridium senile were all taken and consumed readily within the first day. In contrast, $D$. imbricata presented with $C$. californica initially avoided this species, and $40 \%$ of the $D$. imbricata did not feed within $3 \mathrm{~d}$. This difference in selectivity appeared to be related to the anti-predator defenses of the various anemones. These results suggest that ecologists should be careful in employing terms such as 'specialist' or 'preferred prey item' without conducting controlled experiments on prey selection and examining behavioral interactions between predator and prey.
\end{abstract}

\section{INTRODUCTION}

Prey selection by predators may have major effects upon a number of ecological parameters, including the age structure and reproductive tactics of prey populations (Curio, 1976), the distribution of prey species and their competitors (Connell, 1961), and community structure and species diversity (Paine, 1966). Although selectivity can result in specialization, some species may act as ecological generalists when their entire range is considered, but show a high degree of specialization in local populations (Fox and Morrow, 1981).

The leather seastar Dermasterias imbricata (Grube) is a benthic predator, capable of feeding on a wide range of prey organisms, yet it appears to specialize on only 1 or 2 common species of sessile or sedentary prey within any given area. Leather stars have been observed to feed primarily on clonal anemones (Mauzey et al., 1968; Sebens, 1977), sea urchins (Strongylocentrotus purpuratus) in rock depressions (Rosenthal and Chess, 1972), and sea pens (Birkeland, 1974).

\footnotetext{
- Current address of both authors: Department of Zoology, University of California Berkeley, California 94720, USA
}

Sebens (1977) has suggested that predation by seastars on anemones alters the distribution of their prey in some areas. The question we wish to address is whether leather stars actually exhibit any specific prey preferences, or whether these seastars simply prey predominantly on the most common sedentary species in their habitat.

In an effort to examine the importance of prey selection in the foraging behavior of leather stars we conducted a series of investigations in both laboratory and field. The questions we investigated were: (1) What prey species were available in nature, and which of these were taken by free-ranging leather stars; (2) given a choice of several prey species under controlled conditions which would leather stars choose?; (3) how does the defensive behavior of the prey affect the ability of leather stars to feed on that species?

\section{STUDY SITES, MATERIALS AND METHODS}

\section{Field investigations}

Observations were made at 2 major sites, Monterey Coast Guard Breakwater (henceforth referred to as 'the 


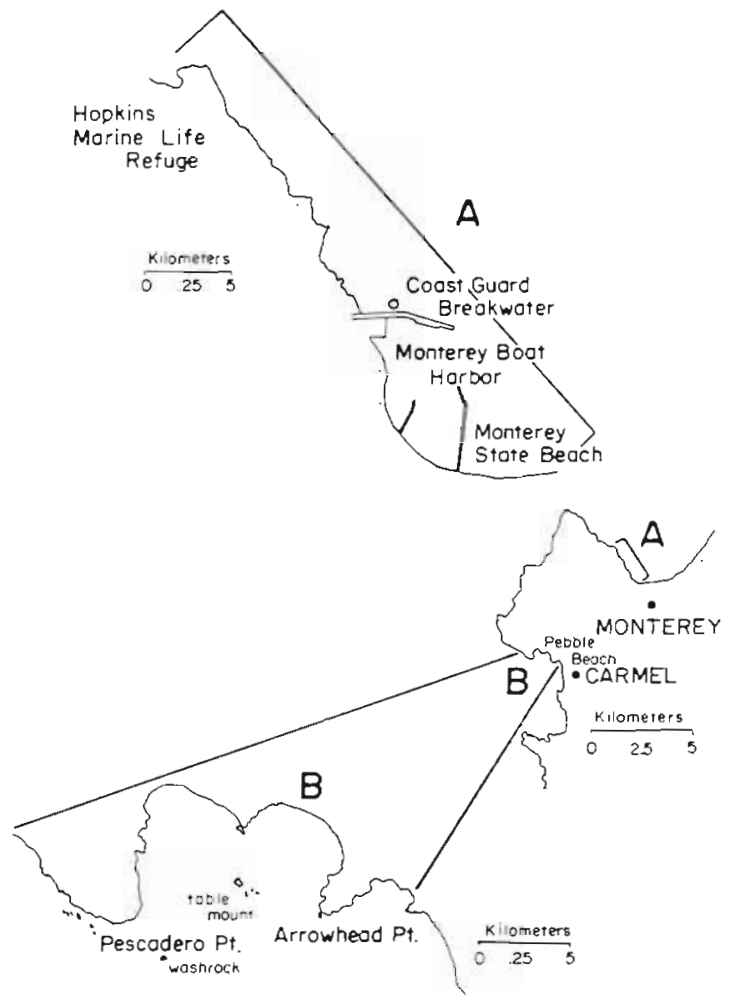

Fig. 1. Monterey Peninsula. (A) Detail of Monterey Coast Guard Breakwater (small circle indicates study site); (B) detail of Stillwater Cove study areas

breakwater'; $121^{\circ} 53^{\prime} \mathrm{N}, 36^{\circ} 36^{\prime} \mathrm{W}$; Fig. 1a) and Stillwater Cove in Carmel Bay (121 $57^{\prime} \mathrm{N}_{i} 36^{\circ} 34^{\prime} \mathrm{W}$; Fig. 1b). Incidental observations were also made in several additional areas, including the waters off Cannery Row in Monterey and the Hopkins Marine Life Refuge in Pacific Grove.

Twenty hours of underwater observations were conducted using SCUBA gear at the breakwater between September 1 and December 9, 1981. The study area was a $50 \mathrm{~m}$ long stretch of the breakwater which extended from the surface to the base of the rocks at $10 \mathrm{~m}$ depth where the boulders and cobbles ended in a sand plain.

In addition, $15 \mathrm{~h}$ of underwater observations were conducted in Stillwater Cove between April and July 1980. Leather stars were found in 3 areas within the cove: (1) Arrowhead Point, (2) on a large table mount at the center of the cove, and (3) at the base of a washrock located at the seaward edge of the cove (Fig. 1b). Each of these areas was characterized by either vertical cliffs ( 2 to $10 \mathrm{~m}$ in height) or large boulders, and was entirely subtidal.

Stomach contents of the leather stars were examined in the field at both sites. The everted stomachs of aII leather stars found during an extensive search of each area were checked for prey. If the stomach was not everted, we forced the stomach and any prey out through the mouth by pressing gently on the aboral surface near the anus. Examinations of leather stars feeding in the lab showed that this was an effective method of checking for prey in this species. Only the most abundant prey item found in the stomach was recorded. This was necessary for two reasons: (1) Most prey were sessile and still attached to the substatum, and hence were inappropriate for collection to quantify and identify in the $1 a b_{i}$ (2) there usually was only 1 prey which made up over $90 \%$ of the biomass of the stomach contents, with other sessile species (which were not taken alone although they were available in single species patches) making up a small proportion. Since species of bryozoans, spirorbids, sponges, and other sessile organisms grow in and amongst patches of anemones, they were probably being taken incidentally, and often were not noticeably digested by leather stars. The numbers of anemones contained within the stomachs of 6 leather stars at the breakwater and 10 leather stars at Stillwater Cove were counted. Although this is impossible to do in most cases because individuals are unrecognizeable after digestion has proceeded for a period of time, in the case of these 16 leather stars digestion had begun only shortly before examination.

The percent cover of subtidal anemones at the breakwater was estimated to determine the type and abundance of prey available to the leather stars. Fiftytwo $1 / 4 \mathrm{~m}^{2}$ aluminum quadrats were randomly placed in the study using a random numbers table. Forty-five quadrats were placed around leather stars in such a way that the leather star was directly in the center of the quadrat. The percent cover of anemones in each of these quadrats was then visually estimated and recorded.

\section{Laboratory investigations}

A total of 46 leather stars were collected from outside of the study area at the breakwater and kept in aquariums from September through December 1981. The area of collection was similar to the study area in prey distribution and density of leather stars. Five of the leather stars were feeding on Anthopleura elegantissima at the time of collection, the rest were feeding on Corynactis californica or were not feeding. No differences in prey choice by these leather stars were ever found in the lab, so they were not treated as separate groups,

Each leather star was measured, photographed, and tagged for identification. The method used for tagging was modified from Rosenthal and Chess (1972). A heavy embroidery needle was used to insert a short 
length of $12 \mathrm{lb}$. test monofilament line under the epidermis near the madreporite. The fishing line was then tied in a loop near the base and variously colored small plastic craft beads were strung in unique combinations on the 2 ends. These tags did not appear to harm the leather stars in any way. We never found any wounds around the tags, any obvious changes in behavior, or any differences in behavior between tagged leather stars and five individually recognizable leather stars which were used as controls.

After tagging, leather stars were held in aquariums for $2 \mathrm{wk}$, and then randomly assigned to 3 treatment tanks. One group of 10 leather stars was placed in a circular tank ( $1.5 \mathrm{~m}$ diameter, $60 \mathrm{~cm}$ depth) and maintained solely on a diet of chopped bait squid (Loligo opalescens) for $6 \mathrm{wk}$. The other 2 groups, consisting of 7 leather stars each, were maintained on a diet of either Corynactis californica (still attached to the rocks collected in the field) or Anthopleura elegantissima (allowed to attach to the bottom of the tank beforehand). Both the anemone and squid diet tanks were provided with flowing, sand-filtered sea water at ambient sea temperatures $\left(\simeq 12\right.$ to $\left.16^{\circ} \mathrm{C}\right)$. After being kept on these restricted diets for $6 \mathrm{wk}$, these 24 leather stars were used in a series of experiments on prey choice.

The prey choice experiments were conducted in a water table $(2 \mathrm{~m} \times 1 \mathrm{~m} \times 20 \mathrm{~cm}$ deep) equipped with running sea water and a constant light cycle (12 h light: $12 \mathrm{~h}$ dark). Experiments were conducted in either the entire water table or in smaller compartments of the water table formed by inserting strips of plexiglass and plastic screen to form fifteen $30 \mathrm{~cm}^{2}$ $(5 \times 6 \mathrm{~cm})$ compartments (see Annett, 1983 for a complete description). Prey were placed in the water table at least $1 \mathrm{~d}$ before experiments were run to allow them to recover from handling. Whenever more than 1 species of prey were used, the anemones were placed in a pairwise fashion so that neighboring anemones or small clumps of anemones were of different species.

The first set of experiments involved Anthopleura elegantissima and Corynactis californica (Table 1.). Three replications were run in the undivided water table using the leather stars from the A. elegantissima, C. californica, and squid diet tanks. In each experiment, leather stars were randomly chosen from the treatment tanks. Leather stars were also randomly allocated to different parts of the water table at the beginning of each experiment to reduce possible sources of bias in prey choice.

Observations were made continuously for the first $2 \mathrm{~h}$ of each experiment and then for at least $1 \mathrm{~h}$ a day until the termination of the experiment. Since leather stars usually settled into long periods of feeding or inactivity after the first $2 \mathrm{~h}$, constant observation was unnecessary, and instead the position and activity of all leather stars and prey were recorded at 1 to $12 \mathrm{~h}$ intervals throughout the experiments. In total, $25 \mathrm{~h}$ of continuous observation and 28 periodic checks were made during the $11 \mathrm{~d}$ of these experiments.

The next set of experiments involved leather stars with a different history. These leather stars were collected from the breakwater and kept in the lab on a diet of squid for 2 to $6 \mathrm{wk}$ before being used in experiments (detailed histories can be found in Annett, 1983). These leather stars were then used in single prey experiments (see below), and 8 of these stars were then used in experiments on choice between Anthopleura xanthogrammica and Corynactis californica. Of these 8 leather stars, 3 had been used in C. californica single prey experiments, 3 in $A$. elegantissima experiments, and 2 had been maintained on squid only for $4 \mathrm{wk}$.

Table 1. Description of Anthopleura elegantissima - Corynactis californica choice experiments

\begin{tabular}{|c|c|c|c|}
\hline & 1 & $\begin{array}{l}\text { Experiment No } \\
2 \mathrm{a}\end{array}$ & $2 b$ \\
\hline \multicolumn{4}{|l|}{ Animals used } \\
\hline D. imbricata & 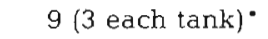 & 12 (4 each tank) & $15(2 a+3$ squid tank $)$ \\
\hline A. elegantissima & 21 & 39 & 26 \\
\hline C. californica & 863 on 12 rocks & 586 on 10racks & 696 on 12 rocks \\
\hline \multicolumn{4}{|l|}{ Size } \\
\hline $\bar{x}$ star radius & $9.5 \mathrm{~cm}(1.5 \mathrm{sd})$ & $9.2 \mathrm{~cm}(1.3 \mathrm{sd})$ & $9.2 \mathrm{~cm}(1.1 \mathrm{sd})$ \\
\hline \multicolumn{4}{|l|}{$\overline{\mathrm{x}}$ diameter } \\
\hline A. elegantissima & $1.9 \mathrm{~cm}(1.1 \mathrm{sd})$ & $2.1 \mathrm{~cm}(0.8 \mathrm{sd})$ & $3.0 \mathrm{~cm}(0.7 \mathrm{sd})$ \\
\hline C. californica & $0.6 \mathrm{~cm}(0.2 \mathrm{sd})$ & $0.6 \mathrm{~cm}(0.2 \mathrm{sd})$ & $0.6 \mathrm{~cm}(0.2 \mathrm{sd})$ \\
\hline \multicolumn{4}{|c|}{ Feeding rate (number consumed) } \\
\hline A. elegantissima & $0.77(13)$ & $0.97(35)$ & $0.48(23)$ \\
\hline C. californica & $0.33 \quad(9)$ & $0.27(10)$ & $0.29(14)$ \\
\hline
\end{tabular}


Each leather star was introduced into separate $30 \mathrm{~cm}^{2}$ compartments containing anemone prey. Observations on the activity of the leather stars were made at 5 to 15 min intervals from the time they were introduced until $3 \mathrm{~h}$ elapsed. From this time until the termination of the experiment periodic checks were made at 1 to $12 \mathrm{~h}$ intervals.

The prey used in these experiments were either Anthopleura elegantissima, A. xanthogrammica, Metridium senile, or Corynactis californica. Small $M$. senile $(\overline{\mathrm{x}}=1.8 \mathrm{~cm}$, sd $=0.27 \mathrm{~cm})$ and $A$. xanthogrammica $(\overline{\mathbf{x}}=1.9 \mathrm{~cm}, \mathrm{sd}=1.15 \mathrm{~cm})$ were used so that their size ranges were similar to that of the $A$. elegantissima used in the experiments $(\overline{\mathrm{x}}=2.5 \mathrm{~cm}$, $\mathrm{sd}=1.23 \mathrm{~cm}$ ). Five leather stars were placed in individual chambers containing $A$. elegantissima, ten with $C$. californica, five with $M$. senile, 8 with $A$, xanthogrammica and $C$. californica, and 3 with A. elegantissima, $C$. californica and $M$. senile.

\section{RESULTS}

\section{Stomach contents of field specimens}

A total of 109 leather stars were examined at Stillwater Cove, and 134 at the breakwater. Of these, 67 and $69 \%$, respectively, were feeding at each location. The Inost commonly taken prey at both locations was the corallimorphian Corynactis californica (Fig. 2). At the breakwater, $84 \%$ of 92 feeding leather stars contained C. californica in their stomachs. Similarly, $62 \%$ of the 73 feeding leather stars examined at Stillwater Cove were feeding on $C$. californica. The median number of C. californica eaten per leather star was 10 at the breakwater (range $=5-44, \mathrm{n}=6$ ) and 5.5 at Stillwater Cove (range $=1-22, \mathrm{n}=10$ ).

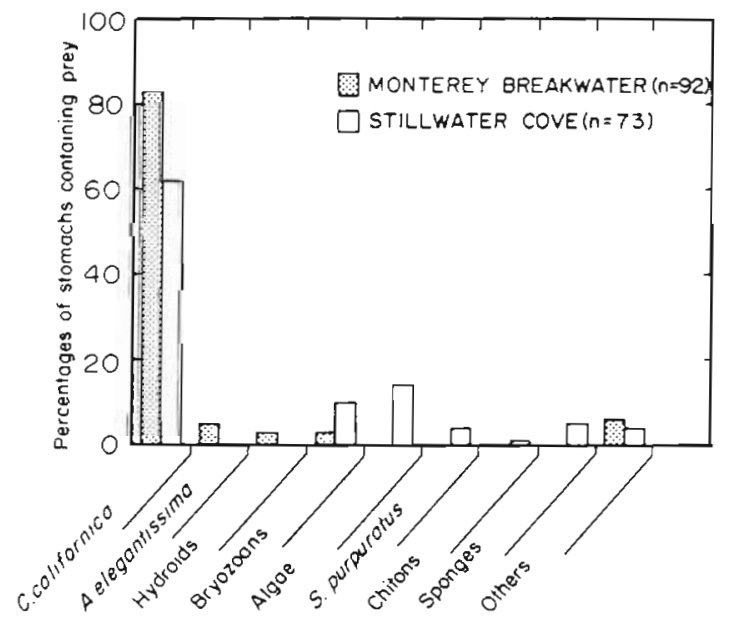

Fig. 2. Frequency distribution of all prey observed taken by leather stars during field observations
A number of other species of prey were also taken at each site (Fig. 2). At the breakwater, the leather stars ate Anthopleura elegantissima (5\%), hydroids (3\%), bryozoans ( $3 \%$ ), and miscellaneous items such as crab moults or barnacles $(5 \%)$. The A. elegantissima were all part of 1 clone found at the edge of the main study area. This clone was located on the top of a boulder in a very shallow area and had 5 leather stars feeding within it. The hydroids consumed were mainly Agalophenia spp. and Abietinaria spp. These hydroids were found as the main prey in a few stomachs; however, they were also found in small amounts in the stomachs of many of the leather stars that were also feeding on Corynactis californica. Since these hydroids commonly grew amongst patches of C. californica, were seldom eaten exclusively, were not taken in the lab, and made up a very small percentage of the biomass of prey in the stomachs, they were not considered to be important prey items. Those bryozoans that were found in stomachs were epiphytic on red algae.

Minor prey species consumed at Stillwater Cover were similar to those at the breakwater, but with a few important differences. Leather stars found at the base of the washrock fed mainly on Corynactis californica and purple urchins Strongylocentrotus purpuratus. The urchins were found in shallow rock depressions, preventing their escape from the leather stars. Leather stars at Stillwater Cove were also found feeding on bryozoans (10\%), the sponge Tethya aurantia (5\%), articulated coralline algae $(14 \%)$, chitons $(1 \%)$, and miscellaneous items such as crab claws and dead scyphozoan medusae $(4 \%)$.

\section{Behavioral observations in the field}

Leather stars were observed while approaching and interacting with prey on several occasions. Three leather stars were seen moving away from partially digested Corynactis californica at the breakwater. Each of these stars was lifting at least 1 arm away from neighboring $C$. californica which had extruded mesenterial filaments to the star's oral surface. We also observed a leather star at Stillwater Cove approach a small group of $C$. californica, contact the tentacles of the anemones, rapidly lift its arms and change direction, thereby avoiding further contact with the anemones.

On 4 occasions when we surveyed the distribution of the leather stars on the table mount at Stillwater Cove we found only 1 or 2 leather stars on the lower $3 \mathrm{~m}$ of the vertical face, but 10 to 18 leather stars on the upper $3 \mathrm{~m}$. Those leather stars on the upper portion were feeding mainly on Corynactis californica, which were absent from the lower portion. However, the solitary 
coral Balanophyllia elegans were common on the lower portion.

Interactions between leather stars and Balanophyllia elegans were observed at the washrock. On 2 occasions we observed leather stars encounter $B$. elegans, and each time the star quickly lifted its arms and altered its movement, leaving the area. Leather stars were never found feeding on $B$. elegans, even in areas where they were found in close proximity.

A few encounters between leather stars and purple urchins were observed at the washrock. We watched a $12 \mathrm{~cm}$ radius leather star unsuccessfully attack a $2.5 \mathrm{~cm}$ radius urchin. The leather star climbed on top of the urchin and humped up the center of its body surrounding the urchin without touching it. During 5 min of observations, the urchin flattened its spines and reached out repeatedly with its pedicellaria and pinched the oral surface of the leather star in a manner similar to that described by Rosenthal and Chess (1972). The leather star did not attempt to evert its stomach and withdrew without feeding. We found several leather stars in this area with detached urchin pedicellaria attached to their oral surfaces, indicating that encounters with urchins may be fairly common.

\section{Prey distribution}

Corynactis californica was the only species of anemone found commonly in the subtidal at the breakwater. C. californica occurred in 44 of the 52 randomly placed quadrats at the breakwater and almost half (21 quadrats) of these contained over $25 \%$ estimated cover of C. californica (Fig. 3). By comparison, Anthopleura elegantissima was not found in any of the quadrats at the breakwater. The clones of A. elegantissima in the intertidal zone at the breakwater usually occurred on the flat tops of boulders, and were spatially separated

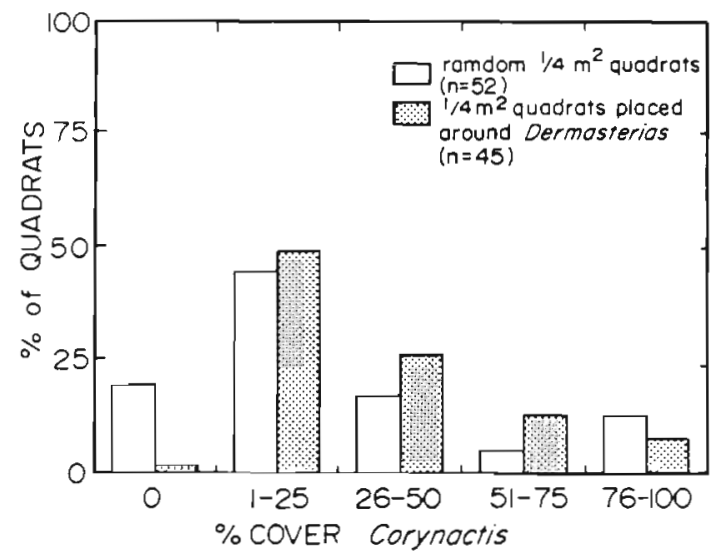

Fig. 3. Percent cover of Corynactis californica within quadrats at the Monterey Coast Guard Breakwater study area from the C. californica, which generally were found on vertical surfaces, by a band of barren rock, green algae, and barnacles. Several large (at least $15 \mathrm{~cm}$ oral disc diameter) A. xanthogrammica were found in the study area but not in the quadrats.

Corynactis californica was the only anemone found in the quadrats placed around leather stars (43 of 45 quadrats). The estimated percentage cover of $C$. californica did not differ significantly between randomly placed quadrats and those placed around leather stars (Fig. 3).

Corynactis californica was also the most common anemone found at Stillwater Cove. These anemones formed a band along the top of the table mount, and were abundant at both the washrock and Arrowhead Point. No Anthopleura elegantissima were found in the study areas, although large $A$. xanthogrammica occurred in small numbers subtidally at Arrowhead Point, and small numbers of Tealia spp. were found at all sites in Stillwater Cove. However, these 2 species were invariably larger than $10 \mathrm{~cm}$ oral disc diameter and were not found as prey in leather star stomachs.

Solitary corals (Balanophyllia elegans and Paracyathis stearnsii) were also found in small numbers within the breakwater study area. A few P. stearnsii occurred in quadrats at the breakwater, and one small group of $B$. elegans was found near the study area. In contrast, $B$. elegans were relatively common at Stillwater Cove, although usually at depths deeper than Corynactis californica. Leather stars were not common on rocks with a high abundance of $B$. elegans.

\section{Feeding behavior and prey choice in the laboratory}

The results of the experiments using Anthopleura elegantissima and Corynactis californica as prey in the undivided water table were consistent in all 3 trials. Twenty-two of 23 leather stars initiated feeding on $A$. elegantissima, and 1 did not feed for the first $72 \mathrm{~h}$ of observation (Table 2). No leather star was observed to feed on $C$. californica as its first prey. The choice of $A$. elegantissima as first prey consumed was independent of previous diet, as leather stars which had been maintained for $6 \mathrm{wk}$ on diets of squid, A. elegantissima, and C. californica were all included in this group (Table 3 ).

Anthopleura elegantissima was also taken most often as subsequent prey. After settling on and consuming their first prey, most of the leather stars remained in the same area and fed on neighboring anemones. Of the 12 leather stars observed during one trial (Table 1, Experiment 2a), 7 fed on A. elegantissima which were grouped together during the first $2 \mathrm{~d}$ of the experiment. These leather stars ate 2 to $5 \mathrm{~A}$. elegantissima in succession before moving to another 
Table 2. Number of Dermasterias imbricata initiating feeding on each of 2 species of prey when presented with both simultaneously. Results from leather stars used in Experiments $2 a, 2 b$, and the 3 leather stars from the squid tank in Experiment $2 b$

\begin{tabular}{|crc|}
$\begin{array}{c}\text { Time to initiation } \\
\text { of feeding (h) }\end{array}$ & \multicolumn{2}{c|}{$\begin{array}{c}\text { Prey species } \\
\text { A. elegantissima }\end{array}$} \\
\hline $0-1$ & $11(6)^{*}$ & 0 \\
$1-24$ & $8(6)$ & 0 \\
$24-48$ & $3(3)$ & 0 \\
$48-72$ & $1(1)$ & 0 \\
Did not feed: 1 & & \\
- Number in parentheses: number of leather stars which \\
had been maintained on a diet other than the prey on \\
which they initiated feeding
\end{tabular}

part of the water table. Three other leather stars fed first on $A$. elegantissima and then on neighboring Corynactis californica. These leather stars had been in contact with $C$. californica while feeding on $A$. elegantissima and did not contact any other A. elegantissima before contacting $C$. californica. Two leather stars fed on $A$. elegantissima which were isolated from other anemones and then moved to another part of the water table, settling on the first $A$. elegantissima which they encountered. One leather star did not feed during these observations. This was a small individual that encountered only C. californica or other, larger leather stars already settled on prey, for the first day after it was placed in the water table. It then moved to a corner of the water table near the drain and was not observed to move again for the duration of the experiment.

The feeding rate for leather stars was higher on Anthopleura elegantissima than Corynactis californica during these experiments (Table 1). During the 3 trials leather stars consumed between 0.48 and $0.97 \mathrm{~A}$. elegantissima $\operatorname{star}^{-1} \mathrm{~d}^{-1}$, compared to only 0.27 to 0.33 C. californica star-1 $d^{-1}$ (Table 1). Since the A. elegantissima were considerably larger than the $C$. californica (Table 1), this difference represents a substantial difference in biomass of each species consumed.

When presented with either Anthopleura xanthogrammica, Corynactis califomica, Metridium senile, or

Table 3. Previous diet and subsequent prey choice of Dermasterias imbricata presented with Corynactis califormica and Anthopleura elegantissima at the same time

\begin{tabular}{|lccc|}
\hline $\begin{array}{l}\text { First choice } \\
\text { as prey }\end{array}$ & $\begin{array}{c}\text { A. elegan- } \\
\text { tissima }\end{array}$ & $\begin{array}{c}\text { Crevious diet } \\
\text { fornica }\end{array}$ & Squid \\
\hline $\begin{array}{l}\text { A. elegantissima } \\
\text { C. californica }\end{array}$ & 7 & 6 & 10 \\
\hline
\end{tabular}

A. elegantissima in individual compartments the leather stars demonstrated a difference in their willingness to feed on some species of prey. All leather stars settled on $A$. elegantissima, A. xanthogrammica, and $M$. senile shortly after encountering these species (Fig. 4). The median time to the initiation of feeding for 5 leather stars fed $M$. senile was $60 \mathrm{~min}$ (range 12 to $120 \mathrm{~min}$ ) and for 6 stars fed $A$. xanthogrammica the median time was less than 60 min (range 15 to 120 min). The median time to the first settlement on prey for 6 leather stars fed $A$. elegantissima was slightly longer (median $=120 \mathrm{~min}$, range 15 to $159 \mathrm{~min}$ ). In contrast, the median time to first settlement on $C$. californica for 6 of 10 leather stars which actually settled was $48 \mathrm{~h}$, with a range of 10 to $72 \mathrm{~h}$ (Fig. 4). Four leather stars did not settle within $3 \mathrm{~d}$ of observation and so were not included in these calculations. The lcather stars in these experiments usually moved around the compartment several times, often encountering $C$. californica, but avoiding any prolonged contact with them.

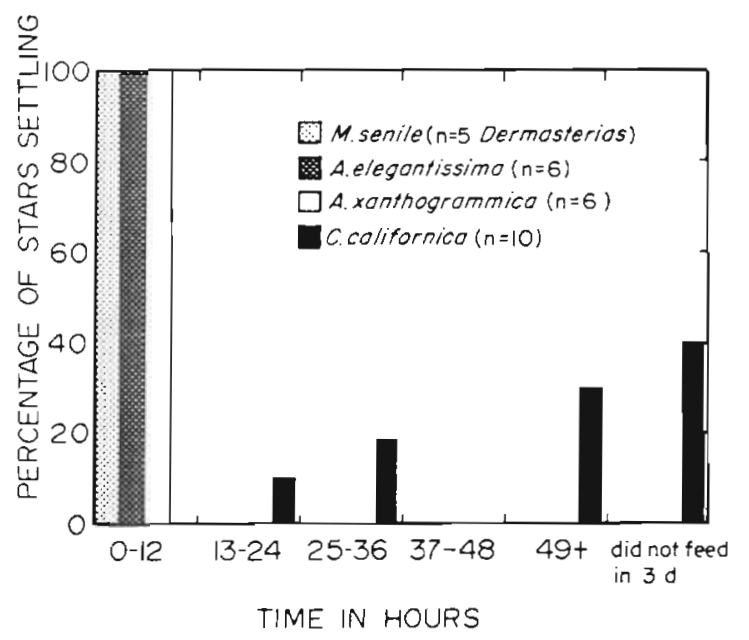

Fig. 4. Time to initiation of feeding for leather stars presented with only a single species of prey

This pattern of readily eating Anthopleura spp. but avoiding Corynactis californica was also observed during the restricted diet pretreatment. When leather stars were held in large tanks containing squid, A. elegantissima, or C. californica prior to the C. californica - A. elegantissima choice experiments described above, leather stars rapidly initiated feeding on A. elegantissima (5 within the first hour, all 7 within the first $12 \mathrm{~h}$ ) and readily consumed them for the entire $6 \mathrm{wk}$ period. However, the leather stars placed in the tank containing $C$. californica did not readily feed on these anemones. No leather star settled on $C$. californica during the first day, and 3 of the 7 leather stars were consistently found on the walls of the tank, away from the anemones. If placed on the bottom, each star 
climbed back onto the walls without settling on prey. These 3 leather stars were not seen to feed on $C$. californica for at least $4 \mathrm{wk}$.

Leather stars were also given a choice between Corynactis californica and Anthopleura xanthogrammica. When placed in compartments containing these 2 anemones, 8 leather stars settled on $A$. xanthogrammica and none on C. californica. All 8 settled on $A$. xanthogrammica during the first day, and 7 of these settled within the first hour (Table 4).

When presented with a choice of Anthopleura xanthogrammica, Corynactis californica, and Metridium

Table 4. Number of individual Dermasteria imbricata initiating feeding on anemones when presented with Anthopleura xanthogrammica and Corynactis californica simultaneously

\begin{tabular}{|ccc|}
\hline $\begin{array}{c}\text { Time to initiation } \\
\text { of feeding (h) }\end{array}$ & \multicolumn{2}{c|}{ Prey species } \\
\hline $0-1$ & 7 & 0 \\
$1-24$ & 1 & 0 \\
$24+$ & 0 & 0 \\
\hline
\end{tabular}

senile, all 3 leather stars settled on $A$. xanthogrammica. These leather stars consumed $A$. xanthogrammica, then $M$. senile, but not $C$. californica during the $2 \mathrm{~d}$ of observations.

\section{Predator prey interactions in the laboratory}

The defensive behavior used by each species of anemone differed in several respects. The most obvious differences were in the use of acontia by $M e$ tridium senile and the use of mesenterial filaments by Corynactis californica. Other observed differences included whether or not anemones retracted their tentacles or remained expanded, or whether anemones released from the substratum after contact with the leather stars (Table 5).

We observed 4 attacks by leather stars on Metridium senile. On each occasion, the $M$. senile retracted their tentacles and extruded acontia from their columns as the leather star began to settle on them. In 3 of the 4 attacks, the leather star first touched the anemone's tentacles, then lifted up its arms and proceeded forward with raised arms before settling. In the fourth attack, the leather star tolerated prolonged contact with the tentacles before settling onto the anemone. As the star settled, the anemone retracted its tentacles. Leather stars were never observed to attempt to avoid contact with the acontia.

Twenty-eight of 32 Anthopleura xanthogrammica were observed to contract when touched by leather stars. The remaining 4 anemones did not contract, but instead moved their tentacles to contact the leather stars. Leather stars invariably settled on $A$. xanthogrammica shortly after encountering them. Eight of the 12 leather stars observed feeding on $A$. xanthogrammica moved directly on top of these anemones without hesitation. The remaining 4 leather stars were observed to lift their arms up and away from the anemones before settling. Four of the A. xanthogrammica which contracted when contacted by the stars released from the substratum and floated upside down.

Anthopleura elegantissima often did not retract their tentacles when contacted by leather stars. Many individuals remained expanded for several hours while underneath leather stars which were feeding on neighboring anemones. On 15 separate occasions $A$. elegantissima individuals were observed to remain expanded after being attacked by a leather star, and several of these remained opened for more than $1 \mathrm{~h}$ after being settled upon. On 7 other occasions, individual $A$. elegantissima were observed to retract their tentacles when touched by a leather star.

Eight of 24 leather stars were observed to move away without settling after first encountering Anthopleura elegantissima, while the remainder settled within minutes after first encounter. The anemones which were successful in repelling attacks usually remained open, and were able to touch the aboral surface of the leather stars with their tentacles. Contact by the tentacles of the anemone caused the rapid contraction of the dermal papulae of the leather star, and this often

Table 5. Summary of anti-predator behavior by anemones observed during contact with leather stars

\begin{tabular}{|c|c|c|c|c|c|}
\hline \multirow[t]{2}{*}{ Species } & \multicolumn{5}{|c|}{ Defense or escape behavior } \\
\hline & $\begin{array}{l}\text { Remained } \\
\text { expanded }\end{array}$ & $\begin{array}{l}\text { Retracted } \\
\text { tentacles }\end{array}$ & $\begin{array}{c}\text { Used } \\
\text { acontia }\end{array}$ & $\begin{array}{l}\text { Used } \\
\text { filaments }\end{array}$ & $\begin{array}{l}\text { Released from } \\
\text { substratum }\end{array}$ \\
\hline A. elegantissima & +1 & + & na & na & + \\
\hline A. xanthogrammica & - & + & na & na & + \\
\hline M. senile & - & + & + & na & + \\
\hline C. californica & + & + & na & + & - \\
\hline
\end{tabular}


resulted in the withdrawal of the leather star's arm. One A. elegantissima which was exceptionally large (9 $\mathrm{cm}$ oral disc diamenter) was particularly successful at avoiding attacks in this fashion. On numerous occasions over a two month period various leather stars were observed to contact the base of this anemone, at which point the anemone bent its column and contacted the star with its tentacles. Immediately after this contact the leather stars then withdrew from contact. This anemone was finally eaten by a leather star which managed to approach it from above by moving off a neighboring rock and onto the top of the anemone. The leather star remained suspended several $\mathrm{cm}$ above the floor for several minutes before the anemone contracted its body. In a natural wave-washed environment, the leather star probably could not have maintained such a precarious position for so long a time.

The greatest number of observed encounters were between leather stars and Corynactis californica, because $C$. californica were often encountered but seldom eaten by leather stars. The $C$. californica used in these experiments were fully expanded most of the time. Whenever leather stars encountered the tentacles of $C$. californica, they rapidly lifted their arms away and retracted the tube feet and dermal papulae on the arm which had made the contact. On 39 occasions we observed leather stars to move their arms rapidly away after contact with a $C$. californica. This behavior was often repeated several times, and the leather stars generally altered their movements or body positions to avoid further contact with C. californica. On only 6 occasions did we observe leather stars to maintain any prolonged contact with $C$. californica. Five of these seastars were touching closed $C$. californica adjacent to Anthopleura elegantissima upon which they were feeding. On at least 3 occasions, we observed leather stars leave $A$. elegantissima after settling upon them when they were touched by $C$. californica.

Mesentarial filaments were also used by Corynactis californica, apparently as defensive structures. On 6 different occasions, we observed leather stars to lift their arms away from $C$. californica which had extruded mesentarial filaments. The nematocysts of these filaments appeared to penetrate the epidermis and the filaments remained attached when the arm was moved. In each case, the leather star had been feeding on neighboring anemones for several hours.

\section{DISCUSSION}

Although Dermasterias imbricata were observed to feed primarily on the corallimorpharian anemone Corynactis californica under natural conditions $(84 \%$ of diet at the breakwater, $62 \%$ of the diet at Stillwater
Cove), specimens of $D$. imbricata appeared to avoid $C$. californica when given a choice of anemone prey in the laboratory. This apparent paradox can be understood if we examine patterns of prey availability, prey responses to predation attempts, and the defensive structures of all species involved.

Corynactis californica was the most abundant species of anemone in both study areas (Fig. 3 and own obs.). In these areas, Anthopleura elegantissima were common intertidally, but were virtually absent subtidally. Only large individuals of $A$. elegantissima and A. xanthogrammica were found subtidally in areas where we observed leather stars. The only common cnidarian other than $C$. californica was the solitary coral Balanophyllia elegans, upon which leather stars were never observed to feed.

Another investigation of the interaction between leather stars and anemone prey (Sebens, 1977), has demonstrated that Anthopleura elegantissima could oniy survive in the subtidal zone if they were protected from leather stars. Sebens also suggested that one reason that small individuals of $A$. xanthogrammica occur in the intertidal is to avoid predation by leather stars, and that leather star predation sets a lower limit on the distribution of small individuals of both species of Anthopleura where these predators and prey are found to co-occur. This is similar to the observations of Paine (1974) that predation by Pisaster ochraceous limits the lower distribution of mussels.

The sharp lower boundary observed in these studies was similar to that found at the breakwater. Clones of Anthopleura elegantissima ended abruptly and were not found in areas occupied by leather stars. Only large A. xanthogrammica and possibly A. elegantissima were found in our study areas. This implies that large individuals may be immune from leather star predation because of their size. We observed no large anemones being taken as prey in the field. In addition, large anemones held in aquariums in our laboratory survived much better than small individuals.

The ability of both large anemones and Corynactis californica to resist predation by leather stars may result from the forms of anti-predator behavior employed. First, large anemones are capable of bending over and touching the aboral surface of the leather star. Presumably, they then discharge nematocysts which cause the dermal papulae to retract, and the star often retreats. Second, some anemones are so large that, even when they are contracted, a leather star attempting to straddle them could not touch the substratum with its tube feet. Leather stars do not attempt to hang onto anemones using their tube feet (own obs.). As a result, a leather star on a large anemone would be vulnerable to being washed off by wave or surge action. Finally, some individual Anthopleura and Met- 
ridium senile employ the escape response of detatching from the substratum. Although this was ineffective in the quiet water of our aquarium, such behavior would be much more effective in turbulent water, where a leather star might have difficulty in holding onto both the subtratum and a buoyant anemone.

Corynactis californica, which does not reach large size and lacks the ability to detach from the substratum, must respond to leather star predation in a different manner. We observed that $C$. californica generally remained expanded when in contact with leather stars, and that $C$. californica would continually place tentacles upon leather stars feeding on their neighbors. We also observed that leather stars showed a tendency to avoid rather than settle on C. californica. In single prey experiments, leather stars took much longer to settle on $C$. californica than on any other species (Fig. 4). Similarly, in the laboratory the rate of feeding on $C$. californica was lower than on Anthopleura elegantissima (Table 1). Although leather stars repeatedly contacted $C$. californica during all prey choice experiments, they chose all other species of anemone preferentially over $C$. californica (Tables 3 and 4). The only other species of cnidarian we observed leather stars to avoid consistently was Balanophyllia elegans.

These behavioral patterns were not altered by recent experience as demonstrated by the similarity in prey choice by leather stars from different diet pretreatments (Corynactis californica, Anthopleura elegantissima, and squid diet tanks). This result is similar to that reported by Ormond et al. (1976) for Acanthaster planci feeding on corals. Since leather star prey choice was not influenced by recent experience, the preference for Anthopleura spp. over $C$. californica remains stable.

These observations suggest that prey defensive behavior is important in determining prey preference. Probably the most important difference in ability to deter leather star predation is the level of irritation caused by the nematocysts of these cnidarians. Although all of these anemones employ nematocysts for defense, Corynactis californica has the largest nematocysts of the 4 species of anemones used in our experiments (Hand, 1954, 1955a, b). The size of these nematocysts may produce stronger mechanical irritation than the smaller nematocysts of Anthopleura spp. and Metridium senile. In support of this argument, Balanophyllia elegans, which was also avoided by leather stars, has even larger nematocysts than $C$. californica.

Although it is possible that toxins contained in the nematocysts produce a chemical irritation, there is currently little information available on the nematocyst toxins of these anemones. It was obvious that some form of irritation, either mechanical or chemical, was experienced by leather stars contacting anemones. Leather stars whose tube feet were pinched with forceps responded similarly to stars contacting Corynactis californica (Annett, 1983). The dermal papulae were withdrawn, tube feet retracted, and body parts lifted away from contact with the anemone. Leather stars generally approached prey with arms uplifted and the tube feet retracted, unlike seastars which specialize on molluscs which approach prey with arms uplifted and tube feet extended. When leather stars assumed a domelike posture over prey, they kept their tube feet retracted with the exception of those not in contact with the prey. This behavior apparently minimizes the exposure of sensitive body parts to defensive structures such as nematocysts or urchin pedicellarias.

The patterns of feeding preference of leather stars are similar in some ways to those described for the predatory nudibranch Aeloidia papillosa by Waters (1973) and Edmunds et al. (1974). Waters reported that A. papillosa fed readily on Anthopleura elegantissima and $A$. xanthogrammica, but tended to avoid Corynarctis californica apparently because of the defensive behavior employed by the latter. However, unlike the results we report for leather stars, Waters found that $A$. papillosa would not consistently feed on Metridium senile in the laboratory. This was apparently due to the effectiveness of acontia at repelling nudibranchs. Although acontia did not appear to do any damage to our leather stars, they became entangled in the cerata of the nudibranchs, causing obvious damage and irritation. However, our observation of predation on $M$. senile by leather stars may be due primarily to the small size of the $M$. senile used. Leather stars can apparently sustain damage after encountering some species of anemones in the field ( $R$. Cohen, pers. comm.).

It is apparent, therefore, that although leather stars are capable of feeding on species such as Corynactis californica which employ large nematocysts for defense, they prefer not to do so unless no other prey is available. Such selective predation may explain the absence of Anthopleura elegantissima and smaller specimens of $A$. xanthogrammica and Metridium senile from our study sites. It is obvious that Anthopleura spp. are capable of existing in this environment, for large individual $A$. xanthogrammica were found in the study areas, and large individuals of A. elegantissima occur at similar depths throughout the Monterey Bay area (own obs.). Therefore, the absence of smaller individuals of these species from areas where leather stars are found suggests that predation by these seastars may be, in part, responsible for this pattern (see Sebens, 1977 for a similar argument).

Our results demonstrate that the apparent 'preference' of leather stars in nature for particular types of 
sessile or sedentary prey, e.g. sea pens (Birkeland, 1974), urchins (Rosenthal and Chess, 1972), or corallimorpharian anemones (this study), are likely to be artifacts resulting from the local extinction of other species of prey, or variation in the abundance of alternative prey once actual 'preferred species' are eliminated. It seems likely, in fact, that the reason for leather star predation on species such as Corynactis californica is that this species is effective enough at anti-predator defense to maintain itself at high density in the face of predation. Since this prey cannot escape, however, persistent predators can take a percentage of the prey despite their anti-predator devices. What results is a form of interspecific war of attrition, with the prey species being unable to prevent predation or escape, and the predator being unable to overcome the defenses of the prey easily. Such prey are taken not because they are preferrcd, but simply because they are what is available to the predator. In a similar vein, the predator cannot be said to 'specialize' on such prey. All that the seastar is doing is exploiting the most common species of potential prey that its limited locomotory capability allows it to capture.

As a result of this pattern, 2 general cautions should be taken by ecologists investigating foraging patterns and prey choice. First, an organism may appear to be a 'specialist' because only 1 species of prey is available, or because it has eliminated all species but 1 from its immediate habitat. Second, a species which appears to be 'preferred' in nature may be taken only because other species, which are actually preferred, are either absent from the area or have evolved an effective means of predator avoidance (see also Moitozoa and Phillips, 1979 and Harrold, 1982 for other examples of this phenomenon).

Acknowledgements. We would like to thank Dr. John Pearse and the staff of the University of California, Santa Cruz, Long Marine Laboratory for providing help and aquarium space during the laboratory portion of this study. We are grateful to Drs. John Pearse, Chris Harrold, and Dave Phillips for comments on the manuscript. Lyn McMasters prepared the illustrations. Ken Nicholson, Shilo Etter, Barbara Pierson, and the Moss Landing Marine Labs diving program assisted with the field work. Discussions with Drs. James Nybakken, Michael Foster, and Ann Hurley were helpful in designing this study. This investigation was partially funded by a grant from the David and Lucille Packard Foundation.

\section{LITERATURE CITED}

Annett, C. A. (1983). Foraging behavior and prey choice of the leather star, Dermasterias imbricata. M. S. thesis, San Jose State University

Bịkeland, C. (1974). Interactions between a sea pen and seven of its predators. Ecol. Monogr. 44: 211-232

Connell, J. H. (1961). The influence of interspecific competition and other factors on the distribution of the barnacle, Cthamalus stellatus. Ecology 42: 281-294

Curio, E. (1976). The ethology of predation. Springer, New York

Edmunds, M., Potts, G. G., Swinfen, R. C., Waters, V. L. (1974). The feeding preferences of Aeloidia papillosa (L.) (Mollusca, Nudibranchia). J. mar. biol. Ass. U. K. 54: 939-947

Fox, L. R., Morrow, P. A. (1981). Specialization: species property or local phenomenon. Science, N. Y 211:887-893

Hand, C. (1954). The sea anemones of Central California. Part I. The corallimorpharian and athenarian anemones. The Wassman J. Biol. 13: 345-375

Hand, C. (1955a). The sea anemones of Central California Part II. The endomyrarian and mesomyarian anemones. The Wassman J. Biol. 13: 37-187

Hand, C. (1955b). The sea anemones of Central California Part III. The acontiarian anemones. The Wassman J. Biol. 13: $189-251$

Harrold, C. (1982). Escape responses and prey availability in a kelp forest predator-prey system. Am. Nat. 119: 136-139

Mauzey, K. P., Birkeland, C., Dayton, P. (1968). Feeding behavior of asteroids and escape responses of their prey in the Puget Sound region. Ecology 49: 603-618

Moitoza, D. J., Phillips, D. W. (1979). Prey defense, predator preference, and nonrandom diet: the interaction between Pycnopodia helianthoides and two species of sea urchins. Mar Biol. 53: 299-304

Ormond, R. F. G., Hanscomb, M. J., Beach, D. H. (1976). Food selection and learning in the crown-of-thorns starfish, Acanthaster planci (L.). Mar. Behav. Physiol. 4: 93-105

Paine, R. T., (1966). Food web complexity and species diversity. Am. Nat. 100: 65-75

Paine, R. T. (1974). Intertidal community structure: experimental studies on the relationship between a dominant competitor and its principal predator Oecologia 15: 93-119

Rosenthal, R. J., Chess, J. R. (1972). A predator-prey relationship between the leather star, Dermasterias imbricata, and the purple urchin, Strongylocentrotus purpuratus. Fish. Bull. U. S. 70: 205-216

Sebens, K. P. (1977). Habitat suitability, reproductive ecology, and the plasticity of body size in two sea anemone populations (Anthopleura elegantissima and $A$. xanthogrammica). Ph. D. thesis, University of Washington

Waters, V L. (1973). Food preference of the nudibranch Aeolidia papillosa, and the effect of the defenses of the prey on predation. Veliger 15: 174-192 